https://doi.org/10.48009/2_iis_2009_604-613

\title{
SPREADSHEET PROGRAM USAGE FOR TEN JOB TASKS IN ORGANIZATIONS - AN EMPIRICAL INVESTIGATION
}

\author{
Joseph S. Mollick Ph.D. Texas A\&M University-Corpus Christi, Joseph.Mollick@ tamucc.edu
}

\begin{abstract}
The technology acceptance model and the tasktechnology fit model are used as the underlying theoretical base for generating hypotheses about spreadsheet program usage for different tasks for which computers are used. Data collected from businesses in South Texas are used to test hypotheses about the probability of spreadsheet program usage for different job tasks for which computers are used by individuals working in organizations. Computer use for ten job tasks with which spreadsheet usage is positively correlated are: (1)producing report, (2) letters and memos, (3)data storage/retrieval, (4) making decisions, (5)analyzing trends, (6) planning/forecasting, (7)analyzing problems/ alternatives, (8)budgeting, (9)controlling and guiding activities, (10)electronic communications with others.
\end{abstract}

Keywords: Spreadsheet Use, Computer Use, Job Tasks.

\section{INTRODUCTION}

Spreadsheets are one of the most widely used software programs. An important area of research in the management of information driven processes and systems in organizations centers around usage of computers in general and about use of specific computer programs for different job tasks employees perform in organizations $[1,4,10]$. Report of an empirical investigation of usage of spreadsheet programs for ten different job tasks is presented in this paper. The results indicate that whether an employee uses a spreadsheet program depends on the tasks they perform. The findings have implications for business students and professionals who may have to use spreadsheet programs to perform different job tasks in organizations.

Spreadsheet programs are taught in required undergraduate classes in the area of management information systems in business schools in the USA and elsewhere. I wanted to let students of business discover first hand what tasks employees perform using different software packages. As part of this broad question, I focus in this paper on the use of spreadsheet programs for different job tasks in organizations surrounding Texas A\&M University-

Volume X, No. 2, 2009
Corpus Christi where I teach. My expectation was that after being exposed to real professionals' usage of computer applications, students would be motivated to learn to apply different software tools to prepare themselves for the job market.

My second motivation was to partially replicate and extend a study [18] on personal computing acceptance factors using recent data from South Texas area. The study in [18] by Igbaria used data from New Zealand collected in the mid 1990s and analyzed the data set to test some hypotheses based on the technology acceptance model (TAM). Testing the popular Technology Acceptance Model (TAM) based predictions is not the main focus of this paper. Analyses of only a part of the survey data are presented in this paper to focus on assessing the empirical probability of spreadsheet usage for ten different job tasks. My goal here is to try to discover the relationships between ten job tasks for which employees use computers and their use of spreadsheet programs. The question I try to shed light on is: how does the probability that an employee uses Spreadsheets (e.g. Excel or Lotus 1-2-3) in a job vary depending on specific job tasks?

\section{LITERATURE REVIEW}

\subsection{The technology acceptance model (TAM)}

The theory spring board for this study is the information systems theory called the technology acceptance model (TAM). TAM is an information systems theory that models how users come to accept and use a technology. TAM is an attempt to understand attitudes toward technology and predicting usage of technology [2]. The model suggests that a number of factors influence potential users' decision to use a technology presented to them. The most important predictor variables that can explain individuals' use of information technology in organizations are perceived usefulness of the technology and perceived ease of use. Perceived usefulness (PU) was defined by Fred Davis as "the degree to which a person believes that using a particular system would enhance his or her job performance". Davis defined Perceived ease-of-use (PEOU) as "the degree to which a person believes 
that using a particular system would be free from effort" [7,8]. In the stream of research involving the TAM, the dependent variables that are used are intention to use a tool or a system, or actual usage of an information technology or system. To measure the dependent variable computer usage, which the TAM model attempts to explain and predict, researchers have used items such as frequency of computer use, hours of computer use per day or week, computer use for different job tasks and usage of different types of application software. While the relationships between the independent and dependent variables in the TAM have been tested in many studies, not enough attention has been paid to the nature of the relationships between computer usage for different specific job tasks and usage of specific types of application software by employees as they perform their jobs. This is where this current study attempts to make a contribution - to show how use of a specific type of application software, such as a spreadsheet software, depends on the specific job tasks that users want to perform. One value of this study is its theory driven practical orientation. It is an investigation of relationships among the items used to measure computer usage, the most prominent dependent variable in the line of research involving the TAM. The study by Igbaria et al (1997) from which the survey questionnaire items for this research were borrowed used data collected from New Zealand. The current study has additional empirical value in that it is based on data from a different country, region and time and a different phase of the evolving information age.

\subsection{The task-technology fit (TTF) model}

In their Task-technology fit (TTF) theory, Goodhue and Thompson [15] theorize that IT is more likely to have a positive impact on individual performance and be used if the capabilities of the IT match the tasks that the user must perform. Goodhue and Thompson [15] developed a measure of task-technology fit that consists of 8 factors: quality, locatability, authorization, compatibility, ease of use/training, production timeliness, systems reliability, and relationship with users. The TTF model has been applied in the context of a diverse range of information systems including electronic commerce systems and combined with or used as an extension of other models related to IS outcomes [12,13,14] such as the technology acceptance model (TAM). In light of the TTF model, arguments can be made that a specific technology or software tool is used if it fits the task that an individual is trying to do.

\subsection{Computer use for different job tasks in light of TAM and TTF Model}

Computer usage is a heavily researched topic in the field of management information systems. Researchers attempt to predict and explain computer usage by individuals in performing jobs in organizations and in personal lives. However, computer usage for specific job tasks can be understood in light of evolutionary biology and anthropology of human behavior related to tools. Tools are used by human beings to enhance their natural abilities to acquire things needed for survival. Computer usage by human beings to perform different job tasks can also be viewed in light of theoretical concepts such as technology adoption life cycle [5] and diffusion of innovations [21]. There are innovators, early adopters, early majority, late majority and laggards among users of new innovations. Computer programs are new innovations whose diffusion and adoption can go through similar cycles or stages. Usage of information technology can be better explained when constructs from the technology acceptance model are combined with constructs from the task-technology fit (TTF) model $[9,23,24,25,26,27,28]$. In the TAM, the focus is on attitudes toward using a particular information technology (IT) which users develop based on perceived usefulness and ease of use of the IT [11]. The task-technology fit model focuses on the match between user task needs and the available functionality of the IT. The specific type of IT we study here are spreadsheet software systems. In the current study, hypotheses are supported using constructs and arguments from both the TAM and the TTF model.

\subsection{Software use in light of TAM and TTF Model}

Software use by individuals can be understood in light of the technology acceptance model and the task-technology fit model. A software application is a tool that can be used to perform a task. Thus, a software must be useful for performing a task that an employee in an organization is required to perform. However, if a tool is too complex and difficult to use, a potential user may not be motivated to use such a tool because of its lack of user friendliness and difficulty to use. In light of the TTF model, an employee may evaluate which tool may fit best for which ones of the many tasks that he or she will have to perform. Thus, if the task is simply to write a memo or letter without any graph or chart or table in it, a simple word processor may be the right fit for that task. On the other hand, if the memo or letter may need to contain graphs, charts or tables-a spreadsheet program may be a better fit for creating charts, graphs or tables. 


\subsection{Spreadsheet use}

Before computers came along, a spreadsheet meant a piece of paper with rows and columns for recording financial data for use in comparative analysis. Accounting worksheets are organized by rows and columns, providing a two-way system for analyzing related accounts. An organization's income statement and balance sheet used to be prepared using data collected in this format on spreadsheets. In computer science and information systems, a spreadsheet is an accounting or bookkeeping program that displays data in rows and columns on a screen. However, the uses of spreadsheet have gone far beyond the profession of accounting or business - and now an ever increasing variety of professionals are using electronic spreadsheet programs to do different job tasks. An electronic spreadsheet can be used as a forecasting tool to project the impact of interest rate changes on a deposit or a loan portfolio during future time periods. Budgeting, financial planning and what if analyses are common tasks where a spreadsheet software can be very useful. Some basic operations in a spreadsheet software include scrolling, selecting and editing cells, filling adjacent cells, copying, inserting, deleting, moving, exporting and importing data, entering and sorting data, formatting numbers and text, aligning text, using built-in functions. A spreadsheet software allows users to create simple lists, tables, apply mathematical and statistical functions [3] to data sets and visualize data sets using charts and graphs. In a spreadsheet program, any cell may contain either data or a formula that describes the value that should be inserted in that cell based on the values in other cells. When one makes a change in one cell, the program automatically recalculates the contents of all cells affected by the change. This automatic recalculation of all related cells is one of the most useful features of a spreadsheet program, making it one of the most widely used business application programs. In light of some of the constructs from the TAM and TTF model, it can be argued that a spreadsheet software will be used if it is easy to use, perceived by potential users to be useful and effective in analyzing and solving problems and if it represents a good fit between the task at hand of the potential user of the software.

\subsection{Research hypotheses}

Ten research hypotheses about the relationship between computer use for each of the ten tasks for which computers are used and spreadsheet use are presented in Table 1. Brief arguments to support each hypothesis are also presented in Table 1.

Table 1: Research hypotheses about relationships between 10 job tasks and spreadsheet use

\begin{tabular}{|l|l|l|}
\hline Task for which computer is used & Hypothesi & Arguments to support hypotheses \\
\hline Producing reports & $\mathrm{H} 1: \mathrm{r} \geq 0$ & Reports require data analysis \\
\hline Letters and Memos & $\mathrm{H} 2: \mathrm{r} \geq 0$ & Letters and memos need charts, tables \\
\hline Data Storage/Retrieval & $\mathrm{H} 3: \mathrm{r} \geq 0$ & Data retrieved from databases for analysis in spreadsheet \\
\hline Making Decisions & $\mathrm{H} 4: \mathrm{r} \geq 0$ & Decision making requires data analysis \\
\hline Analyzing Trends & $\mathrm{H} 5: \mathrm{r} \geq 0$ & $\begin{array}{l}\text { Analyzing trends often require simple statistical functions found in } \\
\text { spreadsheet programs }\end{array}$ \\
\hline Planning/Forecasting & $\mathrm{H} 6: \mathrm{r} \geq 0$ & Planning/ forecasting require data analysis \\
\hline Analyzing problems/ alternatives & $\mathrm{H} 7: \mathrm{r} \geq 0$ & $\begin{array}{l}\text { Analysing problems and comparing alternatives require simulation, } \\
\text { scenariio analysis }\end{array}$ \\
\hline Budgeting & $\mathrm{H} 8: \mathrm{r} \geq 0$ & $\begin{array}{l}\text { Budgeting is quantitative planning that require resource allocation and } \\
\text { related computation }\end{array}$ \\
\hline Controlling and Guiding Activities & $\mathrm{H} 9: \mathrm{r} \geq 0$ & $\begin{array}{l}\text { Activity schedules, time sheets, performance records can be analyzed } \\
\text { using spreadsheets }\end{array}$ \\
\hline Electronic communications with others & $\mathrm{H} 10: \mathrm{r} \geq 0$ & $\begin{array}{l}\text { Some electronic communications may require tables, charts and } \\
\text { attached appendices that show computations }\end{array}$ \\
\hline
\end{tabular}

\section{DESIGN AND METHODOLOGY}

Students in introductory classes on computer applications for business were sent out to interview five individuals who worked in an organization. A structured questionnaire was given to each student which they used to conduct the interviews and collect data. Most of the interviewers came back with five

Volume X, No. 2, 2009 interviews while a few came back with as few as three completed interviews. Data were collected between 2005 and 2007 from different organizations in south Texas area. The ten tasks and the eight software types on which data were collected were adopted from Igbaria et al (1997). Since the independent variables and the dependent variable were all measured at the nominal scale, resulting in 
categorical data, the methods of analysis chosen for the data set were conditional probability analysis and Chi-squared test of independence and correlation analysis.

To collect data about computer usage for specific job tasks, the survey participants were asked to indicate whether they used a computer to perform each of the ten tasks listed as:(1) producing report, (2) letters and memos, (3) data storage/retrieval, (4) making decisions, (5) analyzing trends, (6) planning/ forecasting, (7) analyzing problems/alternatives, (8) budgeting, (9) controlling and guiding activities, (10) electronic communications with others. It is important to note that computer use is a broader concept that includes the concept of software use. Likewise, software use is a broader concept that includes use of specific category of software programs such as spreadsheet programs.

To collect information about usage of software programs, the survey participants were asked to indicate whether they used any of the following eight types of computer software listed as: (1) Spreadsheets e.g., Excel, Lotus 1-2-3, (2) Word processing e.g. MS Word, (3) Database e.g., Access, (4) Statistical analysis, (5) Electronic mail, (6) Programming languages e.g., COBOL, (7) Graphics, (8) Application packages e.g., accounting or payroll packages.

\section{RESULTS}

Results of descriptive statistics about computer usage for ten different job tasks and about usage of specific types of application software are presented in subsections 4.1 and 4.2, respectively. Results of conditional probability analyses are presented in subsection 4.3. In sub-section 4.4, you can read the results of tests of significance of correlation coefficients between each of the ten job tasks for which computers are used and the dependent variable, spreadsheet use. Results of Chi-squared tests for independence of categorical variables are also presented in sub-section 4.2. Results of data analyses are discussed in light of their implications for the research hypotheses presented earlier.

\subsection{Usage of computers for ten job tasks}

The bar chart in Figure 1 shows the percentages of respondents who said they used computers to perform ten different job tasks.

Figure 1: Tasks for which computers are used by a sample of 383 employees

\section{Tasks for Which Computer is Used}

0.90

0.80

0.70

0.60

0.50

0.40

0.30

0.20

0.10

0.00

Tasks 
For example, Figure 1 shows that $84.33 \%$ of the respondents said they used a computer to communicate with others. Communicating with others is the most frequent reason for employees to use a computer. The task for which a computer is second most frequently used is data storage and retrieval: 83.81 percent of the respondents said they used a computer to store and or retrieve data. On the lower end, the task for which a computer is least frequently used is analyzing trends: only $40.99 \%$ of the respondents use a computer to analyze trends.

\subsection{Usage of eight different types of application software}

The bar chart in Figure 2 shows the percentages of 383 respondents who said they used eight different types of computer software to do their job.

Figure 2: Use of eight software packages by a sample of 383 employees

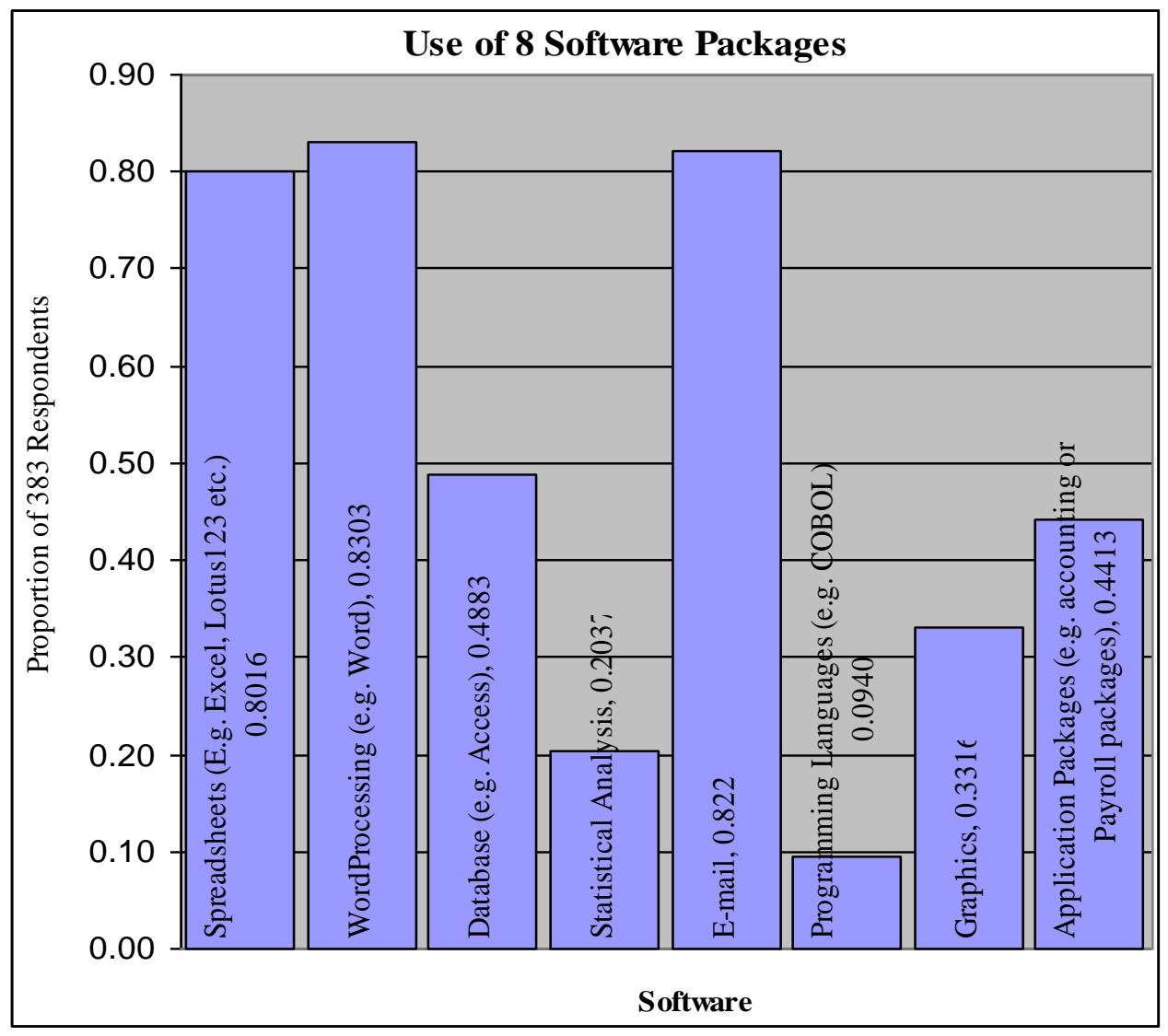

\subsection{Spreadsheet use}

Figure 2 shows that $80.16 \%$ of the respondents use spreadsheet programs to do their jobs. In other words, the probability that a randomly selected employee from this sample of 383 respondents will say that he or she uses a spreadsheet software to do his or her job is 0.8016 . Using the complement rule of probability, about $19.84 \%$ of the respondents do not use a spreadsheet software to do their jobs.

\subsection{Analysis of dependence of spreadsheet use on computer use for job tasks}

An event A is dependent on event B if probability of the event A differs depending on whether event $B$ has occurred or not. For example, in the context of using computer for Task1, producing reports, and spreadsheet use, if $\mathrm{P}($ spreadsheet use $)=$ $\mathrm{P}($ Spreadsheet use | Computer is used for Task1), then spreadsheet use and computer use for Task 1 are independent events; otherwise, they are dependent events. The probability of spreadsheet use for any randomly selected employee from the sample space of 383 respondents is $307 / 383=0.8016$. However, as Table 2 and Figure 3 show, the probability of spreadsheet use increases for those who use computers for a specific job task. On the contrary, the probability of spreadsheet use decreases for those who do not use computers for a specific job task. Spreadsheet use is dependent on each of the ten job tasks listed in our study for which computers are 
used. We discuss how each of the ten examples of job tasks for which a computer is used by an employee, influences the probability of spreadsheet use by an employee.

Table 2: Dependence of spreadsheet software use on computer use for ten job tasks

\begin{tabular}{|l|l|l|l|l|}
\hline $\begin{array}{l}\text { Dependence of the event of spreadsheet use } \\
\text { on job task performed using a computer }\end{array}$ & Task \# & $\begin{array}{l}\text { P when } \\
\text { Task= } \\
\text { No }\end{array}$ & $\begin{array}{l}\text { P when } \\
\text { Task= Yes }\end{array}$ & $\begin{array}{l}\text { Difference in } \\
\text { Probability of } \\
\text { Spreadsheet } \\
\text { Use }\end{array}$ \\
\hline (1) Producing report & Task1 & 0.4545 & 0.8918 & 0.4373 \\
\hline (2) Letters and memos & Task2 & 0.3421 & 0.9153 & 0.5732 \\
\hline (3) Data storage/retrieval & Task3 & 0.4032 & 0.8785 & 0.4753 \\
\hline (4) Making decisions & Task4 & 0.7005 & 0.9337 & 0.2333 \\
\hline (5) Analyzing trends & Task5 & 0.7168 & 0.9236 & 0.2068 \\
\hline (6) Planning/forecasting & Task6 & 0.6919 & 0.9189 & 0.2270 \\
\hline (7) Analyzing problems/alternatives & Task7 & 0.6798 & 0.9441 & 0.2643 \\
\hline (8) Budgeting & Task8 & 0.7073 & 0.9101 & 0.2028 \\
\hline (9) Controlling and guiding activities & Task9 & 0.7128 & 0.8936 & 0.1808 \\
\hline (10) Electronic communications with others & Task10 & 0.5833 & 0.8421 & 0.2588 \\
\hline
\end{tabular}

Figure 3: Differences in probability of spreadsheet use depending on computer use for ten job tasks.

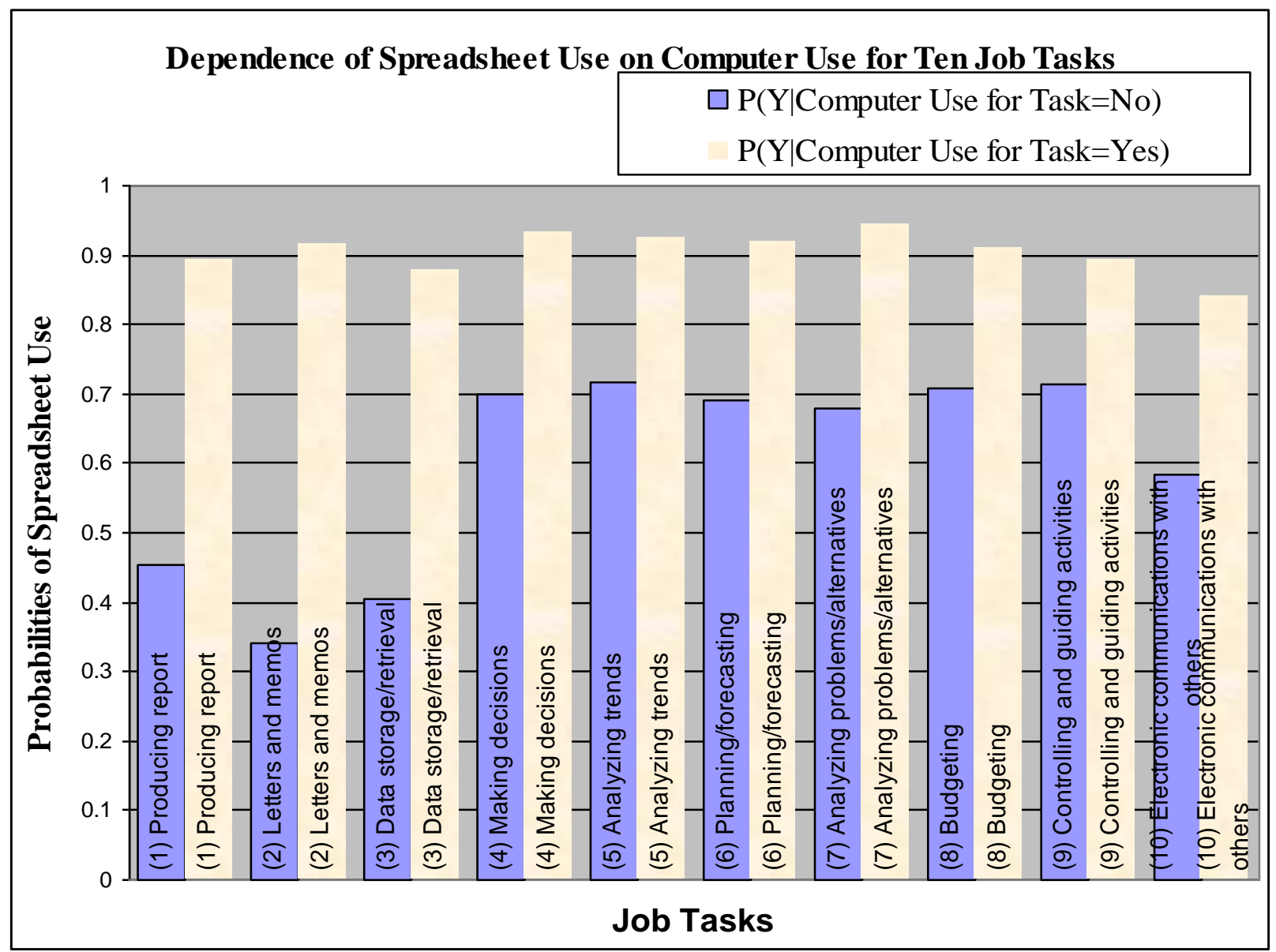




\subsubsection{Computer use for producing reports, and spreadsheet use}

For the first example, among those who use computers for producing reports, $89.18 \%$ use a spreadsheet program. Among those who do not use computers for producing reports, only $45.45 \%$ use a spreadsheet program. This 0.4373 difference in probability indicates that using computers for producing reports and using a spreadsheet program are positively related, dependent events. This is consistent with research hypothesis $\mathrm{H} 1$.

\subsubsection{Computer use for letters and memos and spreadsheet use}

For the second example, among those who use computers for producing letters and memos, $91.53 \%$ use a spreadsheet program. Among those who do not use computers for producing letters and memos, only $34.21 \%$ use a spreadsheet program. This 0.5732 difference in probability indicates that using computers for letters and memos and using a spreadsheet program are positively related, dependent events. This is consistent with research hypothesis $\mathrm{H} 2$.

\subsubsection{Computer use for data storage/retrieval and spreadsheet use}

For the third example, among those who use computers for data storage/retrieval, $87.85 \%$ use a spreadsheet program. Among those who do not use computers for data storage/retrieval, only $40.32 \%$ use a spreadsheet program. This 0.4753 difference in probability indicates that using computers for producing reports and using a spreadsheet program are positively related, dependent events. This is consistent with research hypothesis H3.

\subsubsection{Computer use for making decisions and spreadsheet use}

For the fourth example, among those who use computers for making decisions, $93.37 \%$ use a spreadsheet program. Among those who do not use computers for making decisions, only $70.05 \%$ use a spreadsheet program. This 0.2333 difference in probability indicates that using computers for making decisions and using a spreadsheet program are positively related, dependent events. This is consistent with research hypothesis $\mathrm{H} 4$.

\subsubsection{Computer use for analyzing trends and spreadsheet use}

For the fifth example, among those who use computers for analyzing trends, $92.36 \%$ use a spreadsheet program. Among those who do not use computers for analyzing trends, only $71.68 \%$ use a spreadsheet program. This 0.2068 difference in probability indicates that using computers for analyzing trends and using a spreadsheet program are positively related, dependent events. This is consistent with research hypothesis H5.

\subsubsection{Computer use for planning / forecasting and spreadsheet use}

For the sixth example, among those who use computers for planning/forecasting, $91.89 \%$ use a spreadsheet program. Among those who do not use computers for planning/forecasting, only $69.19 \%$ use a spreadsheet program. This 0.2270 difference in probability indicates that using computers for planning / forecasting and using a spreadsheet program are positively related, dependent events. This is consistent with research hypothesis H6.

\subsubsection{Computer use for analyzing problems / alternatives and spreadsheet use}

For the seventh example, among those who use computers for analyzing problems/alternatives, $94.41 \%$ use a spreadsheet program. Among those who do not use computers for analyzing problems/alternatives, only $67.98 \%$ use a spreadsheet program. This 0.2643 difference in probability indicates that using computers for analyzing problems/alternatives and using a spreadsheet program are positively related, dependent events. This is consistent with research hypothesis $\mathrm{H} 7$.

\subsubsection{Computer use for budgeting and spreadsheet} use

For the eighth example, among those who use computers for budgeting, $91.01 \%$ use a spreadsheet program. Among those who do not use computers for budgeting, only $70.73 \%$ use a spreadsheet program. This 0.2028 difference in probability indicates that using computers for budgeting and using a spreadsheet program are positively related, dependent events. This is consistent with research hypothesis H8.

\subsubsection{Computer use for controlling and guiding} activities and spreadsheet use

For the ninth example, among those who use computers for controlling and guiding activities, $89.36 \%$ use a spreadsheet program. Among those who do not use computers for controlling and guiding activities, only $71.28 \%$ use a spreadsheet program. This 0.1808 difference in probability indicates that using computers for controlling and guiding activities and using a spreadsheet program are positively related, dependent events. This is consistent with research hypothesis $\mathrm{H} 9$. 
4.3.10 Computer use for electronic communications with others and spreadsheet use For the tenth example, among those who use computers for electronic communications with others, $84.21 \%$ use a spreadsheet program. Among those who do not use computers for electronic communications with others, only $58.33 \%$ use a spreadsheet program. This 0.2588 difference in probability indicates that using computers for electronic communications with others and using a spreadsheet program are positively related, dependent events. This is consistent with research hypothesis H10.

\subsubsection{Discussion on usefulness of discovering dependence relationships}

The dependence relationships identified and discussed above can be used to motivate employees and students to use spreadsheet software for different job tasks for which they already use computers, as well as for those tasks for which they do not currently use computers. How spreadsheet software is appropriate for different specific job tasks can be explained to non-users of spreadsheet programs and students of management information systems. Teachers' and software trainers' explanations and arguments in favor of spreadsheet use can be supported with these empirically estimated probability relationships.

\begin{tabular}{|c|c|c|c|c|c|c|}
\hline & & & & P-value of & Chi & |HI..HI \\
\hline $\begin{array}{l}\text { Tasks for which } \\
\text { computers are used }(\mathrm{X} 1 \ldots \mathrm{X} 10)\end{array}$ & $\begin{array}{r}\text { Y=Use } \\
\text { Spreadsheet? }\end{array}$ & $\begin{array}{r}\text { Hypothesized } \\
\text { Correlation }\end{array}$ & Pearson's & (1-tailed) & $\begin{array}{r}\text { Squared } \\
\text { p-value }\end{array}$ & Result? \\
\hline Producing reports & Yes $=1$ & Positive & 0.41865 & 0.0000 & 0.0000 & $\mathrm{H} 1 * * *$ \\
\hline Letters and Memos & Yes $=1$ & Positive & 0.57320 & 0.0000 & 0.0000 & $\mathrm{H} 2 * * *$ \\
\hline Data Storage/Retrieval & Yes $=1$ & Positive & 0.43896 & 0.0000 & 0.0000 & $\mathrm{H} 3 * * *$ \\
\hline Making Decisions & Yes $=1$ & Positive & 0.28985 & 0.0000 & 0.0000 & $\mathrm{H} 4 * * *$ \\
\hline Analyzing Trends & Yes $=1$ & Positive & 0.25496 & 0.0000 & 0.0000 & H5*** \\
\hline Planning/Forecasting & Yes $=1$ & Positive & 0.28443 & 0.0000 & 0.0000 & $\mathrm{H} 6$ **** \\
\hline Analyzing problems/ alternatives & Yes $=1$ & Positive & 0.25857 & 0.0000 & 0.0000 & $\mathrm{H} 7 * * *$ \\
\hline Budgeting & Yes $=1$ & Positive & 0.25361 & 0.0000 & 0.0000 & $\mathrm{H} 8 * * *$ \\
\hline Controlling and Guiding Activities & Yes $=1$ & Positive & 0.22663 & 0.0000 & 0.0000 & $\mathrm{H} 9 * * *$ \\
\hline Electronic communications & Yes $=1$ & Positive & 0.23584 & 0.0000 & 0.0000 & $\mathrm{H} 10 * *$ \\
\hline
\end{tabular}

*** Hypothesis has been supported with $\mathrm{p}$-value less than .001

\section{DISCUSSION AND IMPLICATIONS}

The overwhelming empirical support presented in favor of the ten research hypotheses has implications for theory and practices related to management of information systems and software use in general. The empirical findings have more direct implications for management of spreadsheet use by employees as they perform different job tasks in organizations. The technology acceptance model attempts to predict and explain individuals' behavioral choices concerning

\subsection{Correlation Analyses and Chi-Squared tests for independence of categorical variables}

The correlation coefficients between each of the ten job tasks and spreadsheet use are presented in Table 3 . The job tasks were coded as dummy variables where 1 represented one's use of computers for a specific job task and 0 to represent one's non-use of computers for that specific job task. Likewise, the dependent variable, spreadsheet use, was coded as a dummy variable where $1=\mathrm{I}$ use spreadsheet software and $0=\mathrm{I}$ do not use spreadsheet software. According to the hypotheses developed earlier, all ten correlation values were expected to be positive. So, a one-tailed test of hypothesis was conducted for each of the ten hypotheses to see if the estimated correlation coefficient was statistically significantly greater than zero. Table 3 shows that all ten research hypotheses are supported by the sample data with overwhelming evidence, with p-values less than 0.001 . This means, there is overwhelming evidence in the sample of 383 observations to conclude that spreadsheet use is positively correlated with computer use for specific job tasks in organizations. The p-values associated with Chi-squared tests of independence also indicate that there is overwhelming evidence to conclude that spreadsheet use is dependent on computer use for specific job tasks acceptance and use of computers, software tools and systems. If spreadsheet programs in general and specific tools, procedures and functions in spreadsheet programs can be made easier to use and the usefulness of each of the different tools in spreadsheet programs can be explained to potential users of spreadsheet programs, more individuals will use spreadsheet programs to do tasks for which they use computers anyway. For those who do not currently use computers to perform a specific task, it 
might be that they have not yet been trained or educated about the usefulness, effectiveness, tasktechnology fit and user-friendliness of computer application programs like spreadsheet software programs. To be effective in the marketing of software tools and education and training courses [6] on software tools like spreadsheet programs, it might be helpful to find out what job tasks individuals perform in organizations or would like to perform in future jobs and then explain to them the likelihood of using computers to perform that job and then focus on how tools and procedures in spreadsheet programs can be useful [19, 20] for performing those tasks. Arguments can also be made in light of how good a task-technology fit exists between a task on hand and

\section{REFERENCES}

1. Adams, D. A., Nelson, R. R., \& Todd, P. A. (1992). "Perceived usefulness, ease of use, and usage of information technology: A replication." MIS Quarterly, 16, 227-247.

2. Ajzen, I., \& Fishbein, M. (1980). "Understanding attitudes and predicting social behavior.” Englewood Cliffs, NJ: Prentice-Hall.

3. Apigian, Charles H.; Gambill, Stanley E. "Is Microsoft Excel 2003 Ready for the Statistics Classroom?" Journal of Computer Information Systems, Winter2004-2005, Vol. 45 Issue 2, p27-35.

4. Bagozzi, R. P., Davis, F. D., \& Warshaw, P. R. (1992). "Development and test of a theory of technological learning and usage." Human Relations, 45(7), 660-686.

5. Beal, George M., Everett M. Rogers, and Joe M. Bohlen (1957) "Validity of the concept of stages in the adoption process." Rural Sociology 22(2):166-168.

6. Bedard, Jean C.; Jackson, Cynthia; Ettredge, Michael L.; Johnstone, Karla M. "The effect of training on auditors' acceptance of an electronic work system." International Journal of Accounting Information Systems, Dec2003, Vol. 4 Issue 4, pp227-251.

7. Davis, F. D. (1989). "Perceived usefulness, perceived ease of use, and user acceptance of information technology." MIS Quarterly, 13(3), 319-340.

8. Davis, F. D., Bagozzi, R. P., \& Warshaw, P. R. (1989). "User acceptance of computer technology: A comparison of two theoretical models." Management Science, 35, 982-1003.

9. Dishaw,Mark T.;Strong,Diane M., "Assessing software maintenance tool utilization using task- a software tool such as a spreadsheet program. For individuals involved in developing spreadsheet software tools and developing applications based on spreadsheet programs, it is important to incorporate into programs and applications features such as ease of use [16], usefulness [17] in light of specific tasks to be performed and a good task-technology fit. technology fit and fitness-for-use models", Journal of Software Maintenance: Research and Practice, 1998, 10, 3, 151-179.

10. Dishaw,Mark T.;Strong,Diane M., "Extending the technology acceptance model with tasktechnology fit constructs", Information \& Management, 1999, 36, 1, 9-21.

11. Doll, William J.; Hendrickson, Anthony; Xiaodong Deng. "Using Davis's Perceived Usefulness and Ease-of-use Instruments for Decision Making: A Confirmatory and Multigroup Invariance Analysis." Decision Sciences, Fall98, Vol. 29 Issue 4, p839-869.

12. Goodhue,Dale L., "Development and measurement validity of a task-technology fit instrument for user evaluations of information systems", Decision Sciences, 1998, 29, 1, 105138.

13. Goodhue,Dale L., "Understanding user evaluations of information systems", Management Science, 1995, 41, 12, 1827-1844.

14. Goodhue,Dale L., "Understanding user evaluations of information systems", Management Science, 1995, 41, 12, 1827-1844.

15. Goodhue,Dale L.;Thompson,Ronald L., "Tasktechnology fit and individual performance", MIS Quarterly, 1995, 19, 2, 213-236.

16. Hackbarth, Gary; Grover, Varun; Yi, Mun Y. "Computer playfulness and anxiety: positive and negative mediators of the system experience effect on perceived ease of use." Preview Information \& Management, Jan2003, Vol. 40 Issue 3, p221-232.

17. Hendrickson, A. R., Massey, P. D., \& Cronan, T. P. (1993). "On the test-retest reliability of perceived usefulness and perceived ease of use scales.” MIS Quarterly, 17, 227-230.

18. Igbaria, Magid; Zinatelli, Nancy; Cragg, Paul; Cavaye, Angele L. M.. "Personal Computing 
Acceptance Factors in Small Firms: A Structural Equation Model." Preview MIS Quarterly, Sep97, Vol. 21 Issue 3, pp279-305.

19. Keil, M., Beranek, P. M., \& Konsynski, B. R. (1995). "Usefulness and ease of use: field study evidence regarding task considerations." Decision Support Systems, 13(1), 75-91.

20. Legris, P., Ingham, J., \& Collerette, P. (2003). "Why do people use information technology? A critical review of the technology acceptance model." Information \& Management, 40(3), 191204.

21. Rogers, Everett M. (1962). "Diffusion of Innovations" Glencoe: Free Press.

22. Segars, A. H., \& Grover, V. (1993). "Reexamining perceived ease of use and usefulness: A confirmatory factor analysis.” MIS Quarterly, $17,517-525$.

23. Stewart, T. (1986). "Task fit, ease-of-use and computer facilities." In N. Bjørn-Andersen, K. Eason, \& D. Robey (Eds.), "Managing computer impact: An international study of management and organizations" (pp. 63-76). Norwood, NJ: Ablex.

24. Subramanian, G. H. (1994). "A replication of perceived usefulness and perceived ease of use measurement." Decision Sciences, 25(5/6), 863873.

25. Venkatesh, V., \& Bala, H. (2008). “Technology Acceptance Model 3 and a Research Agenda on Interventions." Decision Sciences, 39(2), 273315.

26. Venkatesh, V., \& Davis, F. D. (2000). "A theoretical extension of the technology acceptance model: Four longitudinal field studies." Management Science, (46:2), 186-204.

27. Venkatesh, V., Morris, M. G., Davis, G. B., \& Davis, F. D. (2003). "User acceptance of information technology: Toward a unified view." MIS Quarterly, (27:3), 425-478.

28. Zigurs,Ilze;Buckland,Bonnie K., "A theory of task/technology fit and group support systems effectiveness", MIS Quarterly, 1998, 22, 3, 313334. 